\title{
Benign Paroxysmal Positional Vertigo Involving Multiple Canals
}

\author{
Alfarghal Mohamad* \\ King Abdul Aziz Medical City-Jeddah , Saudi Arabia
}

Submission: September 22, 2017; Published: September 26, 2017

*Corresponding author: Alfarghal Mohamad, King Abdul Aziz Medical City-Jeddah, Saudi Arabia, Email: audio1972@gmail.com

\section{Opinion}

BPPV is the most common cause of peripheral vertigo, with one year prevalence of $1.6 \%$. It is a mechanical labyrinthine disorder, characterized by recurrent brief, intense vertiginous attacks provoked by head position changes with respect to gravity. Each attack usually lasts for 15 to 60 seconds. It usually has a favorable course that is why it is defined as "Benign", however it sometimes become a disabling condition which affects the patient's quality of life.

Considering the etiology of BPPV, it can be classified into: primary BPPV which occurs spontaneously, some risk factors can increase its incidence such as old age, osteoporosis, vitamin D deficiency and vertebrobasilar insufficiency. Secondary BPPV which occurs on top of ear disorder such as Meniere's disease, vestibular neuritis, vascular and autoimmune labyrinthine disorders, Otosclerosis, chronic suppurative otitis media or following ear surgery. Post traumatic BPPV, when the symptoms developed 24 to 72 hours following head trauma. Head Trauma even the minor ones such as domestic injuries, sports injuries, school injuries and dental care can trigger otoconial detachment leading to the development of the condition [1-3].

There are two main theories to explain BPPV: Canalolithiasis where free floating debris are present in the endolymph filling the canal lumen and Cupulolithiasis when the otoconial debris are attached to the cupula of the affected semicircular canal. Both canalolithiasis and cupulolithiasis cause the cupula of the affected canal to become gravity sensitive leading to the symptoms and characteristic nystagmus when the head moves in the plane of the affected canal with respect to the gravity. BPPV can be classified according to the involved canal/s into: posterior canal BPPV which represent $75-80 \%$ of cases, lateral canal BPPV which represent $15-$ $25 \%$, anterior canal BPPV which is rare and only represent 1-2\% of cases and multiple canals BPPV which represent 6-20\% of cases. The multi-canalar BPPV can occur due to involvement of different canals on the same ear or due to bilateral disease which involves same or different canals in both ears [4].
Diagnosis of BPPV can be easily obtained based on the characteristic history, eliciting the vertigo and characteristic nystagmus with a provoking maneuver such as Dix-Hallpike maneuver, Side-lying maneuver, McClure-Pagnini maneuver (Supine Roll Test) and Choung's bow and lean test . Each semicircular canal has a characteristic excitatory and inhibitory pattern of nystagmus, this is due to the fact that each single semicircular canal is linked to a pair of extra-ocular muscles capable of generating a specific eye movement. It is the type of nystagmus rather than the provoking maneuver which determines the affected canal, as sometimes a specific canal gets stimulated with a maneuver meant to stimulate other canals e.g. horizontal canal can be stimulated on Dix-Hallpike test. When the positional nystagmus is persistent, purely vertical or not eliminated with repeated repositioning maneuvers, MRI Brain should be performed to exclude structural lesions in the central vestibular pathway [5].

Clinicians should differentiate between bilaterally symptomatizing BPPV variants and true bilateral BPPV disease. Horizontal canal BPPV is a bilaterally symptomatizing condition with bipositional bidirectional nystagmus on Supine Roll test, whatever it is geotropic or apogeotropic type. Single anterior canal BPPV can present with downbeating nystagmus on both right and left Dix-Hallpike test. Single posterior canal BPPV can provoke symptoms and nystagmus on Dix-Hallpike test on both sides in a condition called Pseudo-bilateral BPPV or Unilateral mimicking bilateral BPPV, which might happen due to inappropriate head positioning during testing of unaffected ear leading to ampullopetal movements of otoconia on affected posterior canal evoking inhibitory nystagmus. Inappropriate positioning can occur due to the fact that head is put on the required plane based only on the examiner's eye judgment, moreover the limitation of the patient's neck movement, skull form or hair style. In pseudo-bilateral Posterior canal BPPV, usually the affected ear is more symptomatic and treatment of the affected side alleviate symptoms and nystagmus on both sides [6]. 


\section{Bilateral Posterior canal BPPV}

In cases of true bilateral posterior canal BPPV, Dix-Hallpike maneuver provokes the symptoms and the characteristic nystagmus on both sides equally or unequally. As the fact that canalith Repositioning maneuver (Modified Epley's maneuver) for one ear could stimulate the other ear, it is better to use Epley's menauver to treat the more symptomizing side first , followed by treatment of the less symptomatizing side with few days interval in-between , another choice is using Semont's maneuver to treat both sides at the same session as it does not stimulate the none treated side [7].

\section{Multiple canal BPPV}

Most common form of multiple canal BPPV, is the combination of posterior and horizontal canal BPPV, the diagnosis is based on the features of the nystagmus on either maneuvers DixHallpike and McClure -Pagnini maneuver, and in most cases the horizontal nystagmus is geotropic due to canalolithiasis, although cupulolithiasis has been occasionally reported. During DixHallpike maneuver horizontal canal is at least partially stimulated and a horizontal component of the nystagmus may be evident in conjunction with the torsional up beating nystagmus of posterior canal origin, a vertical component of nystagmus may be evident with the horizontal nystagmus of lateral canal origin during the head lateral position test [2].

Clinicians should be careful in mixed horizontal and posterior canal BPPV cases as pseudo-spontaneous nystagmus which is sometimes associated with HC-BPPV with the presence of the typical nystagmus of posterior canal BPPV on Dix-Hallpike test could be confused with cases of acute superior vestibular neuritis associated with secondary posterior BPPV, also in these cases the torsional upbeating nystagmus on Dix-Hallpike test might spontaneously changes its direction to horizontal nystagmus as the nystagmus of horizontal canal origin is usually of longer duration , this might be confused with nystagmus of central origin . Some clinicians prefer to treat the lateral canal BPPV first as it is usually more symptomatic, others prefer to treat posterior canal BPPV first as it is thought to be the reservoir of otoconia. There are many known maneuvers for treatment of horizontal canal BPPV, the most commonly used are: Barbecue (Lempert $360^{\circ}$ ), Gufoni maneuver and Forced Prolonged maneuver which can be used alone or adjunct to any other maneuver.

Mixed Horizontal and anterior canal BPPV is rare as anterior canal involvement is rare, the downbeating component of nystagmus differentiate anterior from posterior canal involvement , the torsional component of nystagmus will show if ipsilateral or contralateral anterior canal is involved, as anterior canal has more chance of self-clearance of otoconia because of its anatomy in relation to gravity, treatment of horizontal canal at first sounds more reasonable. If treatment for the anterior canal BPPV is required, deep head hanging maneuver or its modifications [5].

Other forms of mixed canal BPPV are quite rare, very difficult to diagnose or still considered hypothetical entity. Clinicians need to be capable of identifying the excitatory and inhibitory nystagmus of each canal and need to understand that the net nystagmus pattern of stimulation of more than one canal at the same position is the net vector summation of each component of nystagmus. Correct identification of the affected canal/s , appropriate setting of treatment priorities in cases of multi-canalar BPPV, good counselling of the patient, mastering a back up maneuver for each canal in case of failure of treatment with certain maneuver, repeating the maneuver more than once at the same session with 10 minutes intervals for posterior canal BPPV and 3-5 minutes for other canals, use of head vibrator when cuplulolithiasis is suspected or in resistant cases, avoid lying on the affected side for few days as well as post-treatment instructions for recurrent or resistant cases are tips to improve the outcome of the difficult cases of BPPV [4]. (Keep your eyes open) is the most commonly said sentence for patients in vestibular clinic, and we would like to say it to every clinician examining dizzy patients (Keep your eyes open !̣!).

\section{References}

1. Alfarghal Mohamad, Essam Saleh, $1^{\text {st }}$ edn, (2016) BPPV involving multiple canals in Understanding Benign Paroxysmal Positional Vertigo, Jaypee Brothers Medical Publishers.

2. Asprella Libonati G (2012) Benign Paroxysmal Positional Vertigo and positional vertigo variants. Int J Otorhinolaryngol Clin 4(1): 25-40.

3. Dae Bo Shim, Chang Eun Song, Eun Jung Jung, Kyung Min Ko, Jin Woo Park, et al. (2014) Benign Paroxysmal Positional Vertigo with Simultaneous Involvement of Multiple Semicircular Canals. Korean J Audiol 18(3): 126-130.

4. Dimitris G Balatsouras, George Koukoutsis, Panayotis Ganelis, George S Korres, Antonis Kaberos (2011) Review Article Diagnosis of Single- or Multiple-Canal Benign Paroxysmal Positional Vertigo according to the Type of Nystagmus. International Journal of Otolaryngology.

5. Daniel R Gold, Laura Morris, Amir Kheradmand, Michael C Schubert (2014) Repositioning Maneuvers for Benign Paroxysmal Positional Vertigo. Curr Treat Options Neurol 16: 307.

6. Jeremy Hornibrook (2011) Review Article Benign Paroxysmal Positional Vertigo (BPPV): History, Pathophysiology, Office Treatment and Future Directions. International Journal of Otolaryngology.

7. Miriam Welgampola, Corinna Lechner, Michael Halmagyi (2016) Characteristics of Benign Positional Vertigo Tested on the Epley Omniax Chair. Neurology 86(16): P6-312. 
(C) This work is licensed under Creative BY Commons Attribution 4.0 License DOI: $10.19080 /$ GJO.2017.10.555799
Your next submission with Juniper Publishers will reach you the below assets

- Quality Editorial service

- Swift Peer Review

- Reprints availability

- E-prints Service

- Manuscript Podcast for convenient understanding

- Global attainment for your research

- Manuscript accessibility in different formats ( Pdf, E-pub, Full Text, Audio)

- Unceasing customer service

Track the below URL for one-step submission https://juniperpublishers.com/online-submission.php 